\title{
Assessment of a Brief Intervention with Parents to Prevent Shaken Baby Syndrome ${ }^{1}$
}

\author{
Nahara Rodrigues Laterza Lopes², Suélen Mariana Górni², Victor Oliver Mattar², \\ Lúcia Cavalcanti de Albuquerque Williams ${ }^{2}$ \\ ${ }^{2}$ Universidade Federal de São Carlos, São Carlos-SP, Brazil
}

\begin{abstract}
Shaken Baby Syndrome (SBS) is a form of physical abuse, which may result in serious consequences for child development. Despite its severity, SBS can be prevented through parent training. This study aimed to evaluate the effectiveness of a brief intervention to increase knowledge on SBS with 252 parents. Participants were randomly assigned into two conditions: Experimental Group (EG) and a waiting Control Group (CG). The intervention consisted of exhibition of an educational video and reading a pamphlet on SBS. To measure parental knowledge, the Attitudes towards the Infant Crying Scale was used. An increase in participants' knowledge about consequences of shaking, caregiver's wellbeing, caregiver strategies to deal with crying, beliefs about infant care and about characteristics of infant crying were observed in the EG at posttest, indicating the effectiveness of the intervention.
\end{abstract}

Keywords: violence in children, prevention, parent training, crying

\section{Avaliação de Intervenção Breve com Pais para Prevenção da Síndrome do Bebê Sacudido}

Resumo: A Síndrome do Bebê Sacudido (SBS) é uma forma de maus-tratos físicos que pode acarretar consequências gravíssimas para o desenvolvimento infantil, podendo ser prevenida pela educação parental. Este estudo teve por objetivo avaliar a eficácia de uma intervenção breve para o aumento de conhecimento sobre a SBS em 252 pais. Os participantes foram divididos aleatoriamente em dois grupos: Experimental e Controle de Espera. A intervenção consistiu na exibição de vídeo educativo e leitura de panfleto sobre a SBS. Para avaliação do conhecimento foi utilizada a Escala de Atitudes Frente ao Choro do Bebê. Após a intervenção foi observado no grupo experimental o aumento do conhecimento sobre as consequências de se sacudir o bebê, estratégias para o bem-estar do cuidador, estratégias para lidar com o choro relacionadas ao cuidador, crenças sobre o cuidado do bebê e características do choro do bebê nos primeiros meses de vida, indicando a efetividade da intervenção.

Palavras-chave: violência na criança, prevenção, treinamento de pais, choro

\section{Evaluación de Intervención Breve con Padres para Prevención del Síndrome del Bebé Sacudido}

\begin{abstract}
Resumen: El Síndrome del Bebé Sacudido (SBS) es una forma de abuso físico que puede resultar en consecuencias muy graves para el desarrollo infantil y puede ser prevenido mediante la educación de los padres. Este estudio evaluó la eficacia de una intervención breve para aumentar el conocimiento sobre el SBS con 252 padres. Los participantes fueron divididos aleatoriamente en dos grupos: Grupo experimental y Grupo de control de espera. La intervención consistió en la proyección de un vídeo educativo y de la lectura de un folleto sobre el SBS. Para evaluar el conocimiento se utilizó la Escala de Actitudes Frente al Llanto del Bebé. Después de la intervención, se observó que el grupo experimental obtuvo mayor conocimiento sobre las consecuencias de sacudir a los bebes, estrategias para el bienestar del cuidador, estrategias del cuidador para lidiar con el llanto del bebé, las creencias sobre el cuidado del bebé y las características del llanto del bebé en los primeros meses de vida, indicando la efectividad de la intervención.
\end{abstract}

Palabras clave: violência en niño, prevención, entrenamiento de padres, llanto

\footnotetext{
${ }^{1}$ Article derived from the doctoral thesis of the first author under the supervision of the last author, defended in 2017, in the Graduate Program in Psychology of the Universidade Federal de São Carlos. Support: Foundation for Research Support of the State of São Paulo (Fundação de Amparo à Pesquisa do Estado de São Paulo) (2012/51583-3).
}

Correspondence address: Nahara Rodrigues Laterza Lopes. Universidade Federal de São Carlos. Departamento de Psicologia. Laboratório de Análise e Prevenção da Violência. Rodovia Washington Luís, Km 235, São Carlos-SP, Brazil. CEP 13.565-905. E-mail: nahara.laterza@gmail.com 
Child abuse is a reality in the most diverse societies around the world and is considered a social and public health problem due to the serious consequences it brings to the whole community (Hardcastle, Bellis, Hughes, \& Sethi, 2015). Among the forms of child abuse, the pediatric abusive head trauma (AHT), also known as Shaken Baby Syndrome - SBS (Lopes, Eisenstein, \& Williams, 2013) stands out due to its severity. This form of physical violence occurs when a baby or child under five years of age is violently shaken or abruptly impacted, resulting in cranial or intracranial lesions (Parks, Annest, Hill, \& Karch, 2012).

It is estimated that the mortality rate associated with SBS is greater than $20 \%$, leading to significant deficiencies for two thirds of the survivors (Lindet al., 2016; Parks et al., 2012). Among the main signs of the occurrence of SBS are subdural hematoma, cerebral edema, retinal hemorrhage, and symptoms such as decreased muscle tone, altered state of consciousness, seizures and difficulty feeding and/or breathing. (Lopes et al., 2013).

Despite the absence of studies in Brazil that evaluate the incidence of Shaken Baby Syndrome (SBS), it can be inferred that its occurrence is worrying. Runyan et al. (2010), observed that among 813 mothers interviewed in Embu, São Paula State, 10\% reported having shaken their child under 2 years of age in the last year. In the study by Lopes and Williams (2016a) it was observed that $34 \%$ of the 90 parents interviewed in a municipality in the interior of the State of São Paulo reported that they would shake their babies to stop them crying. Finally, in the study by Fernandes, Silva and Javorski (2010), it was verified that $60 \%$ of 142 professionals of the Family Health Team of a municipality in the interior of Pernambuco State reported having previously shaken a baby. These studies point to the suspicion of frequent occurrence of Shaken Baby Syndrome in the Brazilian context, making it fundamental to develop specific actions for its prevention.

R.G. Barr (2012) argues that, in contrast to other forms of child abuse, SBS has some characteristics that make it a special candidate for public health prevention strategies. Among these characteristics, it is worth highlighting: (1) the high financial cost to deal with its consequences in the most varied governmental sectors, such as health, social security, education and the judicial system; (2) the existence of specific behavior (shaking) and risk factor (baby's crying) associated with its occurrence, which allows preventive messages to be more objective and directed; and (3) the existence of empirical evidence of the efficacy of preventive programs in reducing the incidence of SBS (R.G. Barr, 2012).

Lee, R.G. Barr, Catherine and Wicks (2007) point out that SBS prevention programs should combine the understanding of the specific properties of crying in the first months of the baby's life, the potential that crying has to frustrate caregivers, the limited time for occurrence of inconsolable crying episodes in the baby's development and the understanding that the only negative and serious consequence of crying in the first months is the occurrence of child abuse. Russell, Alpert and Trudeau (2009) further point out the need to teach parents how to deal with the feelings generated by the baby's crying. Emphasizing the importance of the emotional self-regulation of caregivers, these authors highlight the contributions that Psychology can offer to the field of SBS prevention, historically developed by Medicine.

According to Ward, Sanders, Gardner, Mikton and Dawes (2016), the vast majority of child maltreatment prevention programs investigated is developed and applied in developed countries, and, therefore, may not have the same applicability and the same results when carried out in developing countries. Furthermore, the cost of dealing with the consequences of child abuse has an even more significant impact on developing countries, since such countries face higher rates of child abuse, as well as other systemic and equally serious problems (Ward et al., 2016). A possible pathway to cope with the high demand and the lack of infrastructure to deliver parenting programs is the public health approach, that is, an approach that emphasizes prevention and the potential to be applied on a large scale (Ward et al., 2016).

Since most studies on SBS prevention have been conducted in developed countries, it is important to investigate whether other preventive programs, developed in different contexts and cultures, achieve similar results. In this sense, the present study aimed to assess the efficacy of a brief intervention to increase knowledge about SBS in Brazilian parents.

\section{Method}

\section{Participants}

Participated in the study 252 parents, being 159 pregnant women, 36 partners of pregnant woman, 39 mothers and 18 fathers of children up to two years of age. The average age of participants was 26.91 years $(S D=6.85)$, ranging from 14 to 50 years of age. In relation to the marital status, $72.6 \%$ of the participants were married, $18 \%$ were single, $5.9 \%$ were separated and 3.5\% did not report the marital status. Regarding schooling, the average number of years of study was 12.1 years $(S D=4.49)$, ranging from 2 to 23 years of study.

The average monthly income was 3.21 minimum wages $(S D=2.89)$, which corresponds to the socioeconomic stratum $\mathrm{C} 1$, according to Criterion Brazil 2015, which ranged from no income to 14 minimum wages. The average number of children of the participants was $0.74(S D=0.99)$, ranging from 0 to 5 children. Regarding the age of the youngest child of the participants, $71 \%$ were in the gestational phase; $15.9 \%$ were up to 6 months; $5.2 \%$ were between 7 and 12 months and $7.9 \%$ were between 13 and 23 months.

\section{Instruments}

Attitudes towards the Infant Crying Scale. The Attitudes towards the Infant Crying Scale (Lopes, 2017) was used, with the objective of investigating the parents' knowledge about SBS. The scale has six factors, the first one is called Consequences of Shaking the Baby, composed of 10 items 
related to the negative consequences of shaking a baby $(\alpha=0.944)$ as, for example the item "Shaking a baby makes him vomit". The second factor, called Caregiver Well-Being Strategies, is composed of 12 items related to the strategies that caregivers use to feel good about the care of the baby $(\alpha=0.865)$, as, for example, the item "Sleeping well helps the caregiver to take better care of the baby". The third factor, designated by Strategies to Deal with Crying Related to the Baby, is composed of 11 items related to the strategies directed to the baby that the caregivers use to make him stop crying, $(\alpha=0.856)$, as, for example, the item "When the baby is crying a lot, holding him in the lap helps calm him down". The fourth factor, called Strategies to Deal with Baby's Crying Related to the Caregiver, is composed of four items related to strategies aimed at the caregiver to deal with the feelings generated by the baby's crying $(\alpha=0.722)$, as, for example, the item "Listening to music helps the caregiver calm down when he feels nervous about the baby's crying". The fifth factor, called Beliefs about Baby Care, is composed of seven items related to negative beliefs about baby care $(\alpha=0.738)$, as, for example, the item "Fathers should know how to take care of their baby alone". Finally, factor six, called Characteristics of Baby's Crying, is composed of six items that describe the characteristics of the baby's crying in its first months of life $(\alpha=0.688)$, as, for example, the item "Baby's crying is part of normal child development". The respondent should evaluate each item in relation to its degree of agreement using a 4-point Likert scale, with 1 being the "Totally Disagree" option and 4 being the "Totally Agree" option.

Responding to Crying Baby video was developed by The Shaken Baby Prevention Project team at Children's Hospital at Weastmead, Australia, and translated and adapted into Portuguese by the Laboratory for Analysis and Prevention of Violence, Center for Integrated Studies on Childhood, Adolescence and Health (acronym in Portuguese: CEIIAS), by the Zero to Six Institute and by the Special Group on Health in the Child and Adolescent of the Telemedicine University Network (acronym in Portuguese: RUTE). The video, which lasts approximately 3 minutes, shows an excited couple of young parents trying to cope with their son's uncontrollable crying. The main messages transmitted through the video are: (1) "Be father or mother is not easy, it is always doing the best, even when things go from bad to worse"; (2) "The head of the baby is very large and the neck very fragile, you cannot shake at the time of putting to sleep"; (3) "If you shake him, the baby's brain may be injured, causing a serious, even fatal, injury"; (4) "Know that babies usually cry two or three hours a day, it's one of the ways he has to communicate", and (5) information about various strategies for dealing with baby's crying, for example, "Try a gentle massage, sing a song, dance a little, do something different, wrap your baby in a blanket, bring it close to your heart, and take you to a quiet, dark place". The video can be viewed by the website: http://www.youtube.com/watch?v = o0vASBX8CQ0.

Shaken Baby Syndrome pamphlet. This pamphlet was also developed by The Shaken Baby Prevention Project team at The Children's Hospital at The Children's Hospital at Weastmead, Austrália, and has been translated and adapted into Portuguese by the entities previously cited in the video adaptation. The pamphlet presents four main topics: Why is it dangerous to shake the baby? Why would someone shake a baby with violence? What do we know about baby's crying? and How to deal with a crying baby? These topics address information about the baby's crying pattern in the first months of life, the risks of shaking a baby, providing alternative strategies for dealing with the child's uncontrollable crying, and the key messages from the pamphlet "Do not Shake Your Baby" and "Ask for help!".

\section{Procedure}

Data collection. In order to carry out the study, the researchers sought partnerships with Basic Health Units, Family Health Units and other institutions that offered pregnant women groups in six municipalities in the State of São Paulo (Ermelino Matarazzo, Jaú, Dobrada, São Carlos, São Paulo and Taquaritinga). It should be noted that, in relation to the institutions, $32.5 \%$ belonged to the public sector, $53.2 \%$ to the private sector and $14.3 \%$ to the third sector. In each group, the researchers presented the research to the parents and invited them to participate, therefore, it is a sample for convenience. The only inclusion criterion used was to be the father or mother of a child of gestational age or of a child up to two years old. Each group of participants was randomly assigned to a control condition: control group - CG $(n=79)$ or experimental group - EG $(n=175)$. There were no differences between groups for schooling $\left[M_{\mathrm{GE}}=12.77\right.$ (4.34), $\left.M_{\mathrm{GC}}=10.66(4.28), t(231)=3.362, p=0.115\right]$ and income $\left[M_{\mathrm{GE}}=2763.63(2309.67), M_{\mathrm{GC}}=1972.40(2131.92)\right.$, $t(184)=2.180, p=0.085]$, indicating that the randomization was successful.

The brief intervention consisted of two meetings for both EG and CG participants, and was conducted in a group of 2 to 30 parents per meeting. All meetings were conducted by facilitators (second and third authors), specially trained to carry out this research and about the Shaken Baby Syndrome. For EG, in the first meeting, the pre-test, the intervention and the post-test were carried out. At the second meeting, held one month after the first meeting, participants responded to the follow-up. For the CG, in the first meeting only pretest 1 was carried out. After 15 days a new meeting was carried out in which pre-test 2 was applied, being offered the intervention. The pre-test, post-test and follow-up stages consisted of the application of the Attitudes towards the Infant Crying Scale (Lopes, 2017). It should be noted that 69 parents gave up participating in the study after the intervention, claiming difficulties in responding again to the questionnaire.

The intervention, which lasted an average of 15 minutes, consisted of the video Responding to Crying Baby, followed by the reading of the pamphlet and a brief discussion based on a previously prepared script. This discussion was intended to resume with the participants the main points addressed 
by the video and the pamphlet. This strategy has sought to increase the likelihood that parents will use appropriate and safe techniques to deal with baby's crying and decrease the likelihood of abusive events such as SBS.

Data analysis. For the statistical analysis, the score obtained by the participant in each factor of the Attitudes towards the Infant Crying Scale was used. This score was calculated by dividing the sum of the points obtained in the Likert scale in each factor by the number of items of each factor.

In order to evaluate the impact of the intervention on the knowledge of the participants, the scores between the groups (control and experimental) and between the moments of evaluation (pre-test and post-test) were compared simultaneously. After verification of the assumptions to perform a variance analysis with the present sample, an ANOVA subdivided was conducted with the experimental conditions (control and experimental groups) as the factor between participants and the moments of evaluation (pre-test and post-test) as the intraparticipant factor. For this analysis, a level of significance of $5 \%$ was considered. When the interaction between the experimental conditions and the moments of evaluation proved to be significant, additional investigations were conducted using the $\mathrm{t}$-test for independent samples and the t-test for paired samples, adjusting the significance criterion to 0.0125 . In order to investigate the maintenance of the performance after the intervention, the results obtained by the EG participants in the three evaluated periods (pre-test, post-test and follow-up) were submitted to an ANOVA of repeated measures to a factor.

\section{Ethical Considerations}

The study was submitted to the Human Research Ethics Committee of the Federal University of São Carlos, obtaining a favorable opinion (CAAE: 2474713.8.0000.5504, Opinion No 502.815; CAAE: 24260313.0.0000.5504, Opinion No: 444.920). All participants were informed about the objectives of the study and the voluntary, confidential and anonymous nature of the respective participation, and signed the Term of Free and Informed Consent, agreeing to voluntarily participate in the study.

\section{Results}

\section{Impact of Intervention}

The analysis of the subdivided ANOVA revealed interaction effects between the experimental conditions and the moments of evaluation for the factors: Impacts of Shaking the Baby [Pillai's Trace $=0.120, F(1.180)=24.515$, $\left.p<0.001, \eta^{2 / \mathfrak{p}}=0.120, \pi=0.998\right]$; Caregiver Well-Being Strategies [Pillai's Trace $=0.045, F(1,180)=8.522$, $\left.p=0.004, \eta^{2 / p}=0.045, \pi=0.827\right]$; Strategies to Deal with Crying Related to the Baby [Pillai's Trace $=0.077$, $\left.F(1,180)=57.174, p<0.001, \eta^{2 / p}=0.077, \pi=0.970\right]$; Beliefs about Baby Care $[$ Pillai's Trace $=0.102, F(1,179)=20.395$, $\left.p<0.001, \eta^{2 / p}=0.102, \pi=0.994\right]$ and Characteristics of Baby's Crying [Pillai's Trace $=0.151, F(1,179)=31.814$, $\left.p<0.001, \eta^{2 / p}=0.151, \pi=1.000\right]$, indicating that the intervention contributed to a change of knowledge of the participants for these factors.

When analyzing the effect size measures according to the classification proposed by Cohen (1988), it is observed that the intervention had a great effect for the factors: Characteristics of Baby's Crying $\left(\eta^{2 / p}=0.151\right)$, a medium effect for the factors: Impacts of Shaking the Baby $\left(\eta^{2 / p}=0.12\right)$, Beliefs about Baby Care $\left(\eta^{2 / p}=0.102\right)$ and Strategies to Deal with Baby's Crying Related to the Caregiver $\left(\eta^{2 / p}=0.077\right)$, and a small effect for the factor Caregiver Well-Being Strategies $\left(\eta^{2 / \mathfrak{p}}=0.045\right)$. To understand the direction of observed effects, additional investigations were performed using the t-test for independent samples and the t-test for paired samples.

Table 1 presents the average and standard deviation for each of the Factors of Attitudes towards the Infant Crying Scale for CG and EG in the two evaluated moments (pre-test and post-test/pre-test 2 ).

Table 1

Average (and Standard Deviation) for the Attitudes towards the Infant Crying Scale in Each of the Moments Evaluated for Experimental and Control Groups

\begin{tabular}{lcccc}
\hline & \multicolumn{2}{c}{ Experimental Group } & \multicolumn{2}{c}{ Control Group } \\
\hline & Pre-Test & Post-Test & Pre-Test 1 & Pre-Test 2 \\
\hline Impacts of Shaking the Baby & $2.89(0.63)^{\mathrm{b}}$ & $3.52(0.53)^{\mathrm{a}, \mathrm{b}}$ & $2.88(0.51)$ & $3.04(0.53)^{\mathrm{a}}$ \\
Caregiver Well-Being Strategies & $3.27(0.36)^{\mathrm{b}}$ & $3.36(0.40)^{\mathrm{a}, \mathrm{b}}$ & $3.14(0.36)$ & $3.09(0.29)^{\mathrm{a}}$ \\
Strategies to Deal with Crying Related to the Baby & $3.05(0.36)$ & $3.26(0.40)$ & $2.96(0.32)$ & $3.08(0.32)$ \\
Strategies to Deal with Baby's Crying Related to the & $2.54(0.53)^{\mathrm{b}}$ & $3.07(0.55)^{\mathrm{a}, \mathrm{b}}$ & $2.45(0.60)$ & $2.62(0.58)^{\mathrm{a}}$ \\
Caregiver & $2.54(0.47)^{\mathrm{b}}$ & $2.84(0.54)^{\mathrm{a}, \mathrm{b}}$ & $2.50(0.35)$ & $2.52(0.40)^{\mathrm{a}}$ \\
Beliefs about Baby Care & $2.71(0.46)^{\mathrm{b}}$ & $3.26(0.43)^{\mathrm{a}, \mathrm{b}}$ & $2.54(0.43)^{\mathrm{c}}$ & $2.70(0.36)^{\mathrm{a}, \mathrm{c}}$ \\
Characteristics of Baby's Crying & & &
\end{tabular}

Note. Averages on the same line with equal letters are significantly different from each other. For all measurements, higher average values indicate greater knowledge $(p \leq 0.001)$. 
As can be observed, for all factors, the post-test scores of the EG were higher than those of the CG pre-test 2, and these differences were significant for the factors: Impacts of Shaking the Baby $[t(183)=5.767, p<0.001, d=0.90]$; Caregiver WellBeing Strategies $[t(156.615)=5.114, p<0.001, d=0.77]$; Strategies to Deal with Baby's Crying Related to the Caregiver $[t(182)=5.297, p<0.001, d=0.79]$; Beliefs about Baby Care $[t(181)=3.949, p<0.001, d=0.83]$ and Characteristics of Baby's Crying $[t(137.413)=9.460, p<0.001, d=1.41]$. According to Cohen's classification, it was observed that the intervention had a large effect on the factors: Characteristics of Baby's Crying $(d=1.41)$, Impacts of Shaking the Baby $(d=0.90)$ and Beliefs about Baby Care $(d=0.83)$, a medium effect for the factors: Caregiver Well-Being Strategies $(d=0.77)$ and Strategies to Deal with Baby's Crying Related to the Caregiver $(d=0.79)$. These results indicate that the EG presented a greater knowledge in the post-test compared to the CG, especially on the characteristics of baby's crying, the impacts of shaking him and the beliefs about his care.

In relation to EG, the post-test scores were higher than the pre-test scores for all factors, with a significant difference for the factors: Impacts of Shaking the Baby $[t(122)=-10.563$, $p<0.001, d=1.08]$; Caregiver Well-Being Strategies $[t(120)=-6.260, p<0.001, d=0.23]$; Strategies to Deal with Baby's Crying Related to the Caregiver $[t(121)=-10.201, p$ $<0.001, d=0.98]$; Beliefs about Baby Care $(d=0.83)$, and a medium effect for the factors: Caregiver Well-Being Strategies $[t(121)=-8.413, p<0.001, d=0.59]$ and Characteristics of Baby's Crying $[t(120)=-12.670, p<0.001, d=1.23]$. According to Cohen's (1988) classification, it was observed that the intervention had a large effect on the factors: Characteristics of Baby's Crying $(d=1.23)$, Impacts of Shaking the Baby $(d=1.08)$ and Strategies to Deal with Baby's Crying Related to the Caregiver $(d=0.98)$, a medium effect for the factor Beliefs about Baby Care $(d=0.59)$ and a small effect for the factor Caregiver Well-Being Strategies $(d=0.23)$. These results indicate an increase in knowledge after the intervention to the EG, especially on the characteristics of baby's crying, the impacts of shaking him and the strategies to deal with the baby's crying related to the caregiver.

Finally, a significant difference was observed between pre-test 1 and pre-test 2 for the factor Characteristics of Baby's Crying [t(59) $=-3.843, p<0.001, d=0.40]$, being the scores in pre-test 2 higher than in the pre-test 1 . According to Cohen's classification, it is observed that the passage of time had a small effect on the factor: Characteristics of Baby's Crying $(d=0.40)$. Considering that in the post-test/pre-test 2 a significant and large magnitude difference was observed between the EG and the CG for this factor, it can be concluded that despite the passage of time contributed to a change of knowledge about the characteristics of baby's crying, the intervention seems to have influenced this increase more significantly.

Taking into account that the application of the post-test to the EG was performed shortly after the intervention, additional analysis were conducted by means of the subdivided ANOVA comparing the performance of the EG in the pre-test and in the follow-up, occurred after one month of the intervention, with the performance of the $\mathrm{CG}$ in pre-test 1 and pre-test 2 . These analysis had as objective to evaluate if the increase of the knowledge observed in the post-test of the EG, in comparison with the pre-test 2 of the CG, occurred due to the simple memory of the intervention or from the learning of its content. Interaction effects between groups and moments of evaluation were observed for all factors of the scale [Impacts of Shaking the Baby: Pillai's Trace $=0.144, F(1.122)=20.479, p<0.001$, $\eta^{2 / p}=0.144, \pi=0.994$; Caregiver Well-Being Strategies: Pillai's Trace $=0.092, F(1.123)=12.402, p=0.001$, $\eta^{2 / p}=0.092, \pi=0.937$; Strategies to Deal with Crying Related to the Baby: Pillai's Trace $=0.038, F(1,122)=4.762$, $p=0.031, \eta^{2 / p}=0.038, \pi=0.581$; Strategies to Deal with Crying Related to the Caregiver: Pillai's Trace $=0.106$, $F(1.125)=14.831, p<0.001, \eta^{2 / p}=0.106, \pi=0.969$; Beliefs about Baby Care: Pillai's Trace $=0.207, F(1.124)=32.270$, $p<0.001, \eta^{2 / p}=0.207, \pi=1.000$; Characteristics of Baby's Crying: Pillai's Trace $=0.058, F(1.123)=7.536, p=0.007$, $\eta^{2 / p}=0.058, \pi=0.777$, indicating that even after the passage of time, the performance of the EG was higher than the CG as a result of learning the content of the intervention. These results suggest that the intervention was effective in increasing participants' knowledge, especially about the characteristics of the baby's crying and the consequences of shaking him.

\section{Results Maintenance}

An ANOVA of repeated measures to one factor was conducted for all factors of the scale, in order to compare the scores of the EG at the three evaluated moments (pre-test, posttest and follow-up). Table 2 presents the means and standard deviations for each of the factors of the Attitudes towards the Infant Crying Scale in each of the evaluated moments.

Table 2

Average (and Standard Deviation) for the Attitudes towards the Infant Crying Scale in Each of the Moments Evaluated for Experimental and Control Groups

\begin{tabular}{lccc}
\hline & Pre-Test & Post-Test & Follow-Up \\
\hline $\begin{array}{l}\text { Impacts of Shaking } \\
\text { the Baby }\end{array}$ & $2.81(0.08)^{\mathrm{a}, \mathrm{b}}$ & $3.55(0.06)^{\mathrm{a}}$ & $3.50(0.07)^{\mathrm{b}}$ \\
$\begin{array}{l}\text { Caregiver Well- } \\
\text { Being Strategies }\end{array}$ & $3.19(0.04)^{\mathrm{a}, \mathrm{b}}$ & $3.31(0.05)^{\mathrm{a}}$ & $3.37(0.04)^{\mathrm{b}}$ \\
$\begin{array}{l}\text { Strategies to Deal } \\
\text { with Crying Related }\end{array}$ & $2.97(0.04)^{\mathrm{a}, \mathrm{b}}$ & $3.20(0.05)^{\mathrm{a}}$ & $3.21(0.05)^{\mathrm{b}}$ \\
$\begin{array}{l}\text { to the Baby } \\
\begin{array}{l}\text { Strategies to Deal } \\
\text { with Baby's Crying }\end{array}\end{array}$ & $2.50(0.07)^{\mathrm{a}, \mathrm{b}}$ & $3.06(0.06)^{\mathrm{a}}$ & $3.09(0.07)^{\mathrm{b}}$ \\
$\begin{array}{l}\text { Related to the } \\
\text { Caregiver }\end{array}$ & & & \\
$\begin{array}{l}\text { Beliefs about Baby } \\
\text { Care }\end{array}$ & $2.42(0.05)^{\mathrm{a}, \mathrm{b}}$ & $2.73(0.06)^{\mathrm{a}}$ & $2.79(0.06)^{\mathrm{b}}$ \\
$\begin{array}{l}\text { Characteristics of } \\
\text { Baby’s Crying }\end{array}$ & $2.71(0.06)^{\mathrm{a}, \mathrm{b}}$ & $3.28(0.05)^{\mathrm{a}, \mathrm{c}}$ & $3.10(0.05)^{\mathrm{b}, \mathrm{c}}$ \\
\hline
\end{tabular}

Note. Averages on the same line with equal letters are significantly different from each other. For all measurements, higher average values indicate greater knowledge $(p \leq 0.001)$. 
Significant time effects were observed for the factor Impacts of Shaking the Baby [Wilks' Lambda $=0.435$, $\left.F(2.63)=40.874, p<0.001, \eta^{2 / p}=0.565, \pi=1.000\right] ;$ Caregiver Well-Being Strategies [Wilks'Lambda $=0.787$, $\left.F(2.64)=8.639, p<0.001, \eta^{2 / p}=0.213, \pi=0.962\right]$; Strategies to Deal with Crying (Baby) [Wilks' Lambda $=0.607$, $\left.F(2,63)=20.354, p<0.001, \eta^{2 / \mathrm{p}}=0.393, \pi=1.000\right]$; Strategies to Deal with Baby's Crying (Caregiver)[Wilks' Lambda $=0.480, F(2,65)=35.197, p<0.001, \eta^{2 / \mathrm{p}}=0.520$, $\pi=1.000]$; Negative Characteristics of Baby Care [Wilks' Lambda $=0.461, F(2,64)=37.379, p<0.001, \eta^{2 / \mathrm{p}}=0.539$, $\pi=1.000$ ] and Characteristics of Baby's Crying [Wilks' Lambda $=0.380, F(2,63)=51.434, p<0.001, \eta^{2 / \mathrm{p}}=0.620$, $\pi=1.000]$. These results indicate that, when analyzed only the $\mathrm{EG}$, an increase of the scores was observed in all the factors of the pre-test for the post-test and the maintenance of these posttest scores for the follow-up, with the exception of the factor Characteristics of Baby's Crying, that between the post-test and the follow-up showed a statistically significant increase.

\section{Discussion}

The results of the present study indicate that the intervention was effective in increasing participants' knowledge about: impacts of shaking the baby; caregiver well-being strategies; strategies for dealing with baby's crying related to the caregiver; beliefs about baby care and the characteristics of baby's crying in the first few months of life. In addition, the increase in knowledge obtained with the intervention seems to have been maintained after one month of its completion. These results corroborate studies developed in other countries that also observed an increase in parents' knowledge about the baby's crying pattern in the first months of life and the risks of shaking it (R.G. Barr, M. Barr, et al., 2009; R.G. Barr, Rivara, et al., 2009; Deyo, Skybo, \& Carroll, 2008; Foley et al., 2013; Fujiwara, 2015; Fujiwara et al., 2012; Monsalve-Quintero \& Alvarado-Romero, 2010; Morrill, McElaney, Peixotto, VanVleet, \& Sege, 2015; Rodríguez, Marrero, Ortiz, Rios, \& Rivera, 2011; Simonnet et al., 2014; Tasar et al., 2015; Tolliday et al., 2010).

It is also worth noting that the present study presented measures of effect size greater than those observed in previous studies on the efficacy of brief interventions to increase parents' knowledge about the characteristics of crying and the impacts of shaking. In studies involving the PURPLE Crying program, for example, effect size measurements were observed (Cohen's $d$ ) for knowledge about characteristics of crying between 0.39 and 0.83 (R.G. Barr, M. Barr, et al., 2009; R.G. Barr, Rivara, et al., 2009; Fujiwara, 2015; Fujiwara et al., 2012), whereas in the present study an effect size of 1.41 was observed. Regarding knowledge about the consequences of shaking, the same pattern is observed: the Cohen's $d$ (1988) ranged from 0.12 to 0.44 in previous studies on PURPLE Crying (R.G. Barr, M. Barr, et al., 2009; R.G. Barr, Rivara, et al., 2009; Fujiwara, 2015; Fujiwara et al., 2012), whereas in the present study an effect size on the order of 0.90 was observed.
An explanatory hypothesis for this difference in effect size values is related to the fact that the present sample shows lower schooling and age than the previous studies. Another hypothesis is related to the use in the present study of an instrument whose psychometric evidence was investigated (Lopes, 2017), whereas previous studies created questionnaires for the studies, without any indication of their psychometric properties. In addition, another important difference between the previously mentioned studies refers to the use in the present study of the intraparticipant design, that is, the same participants were compared before and after the intervention. In the previous surveys, only the delineation between participants was used, comparing the groups only after the intervention. Finally, it is emphasized that in the present study the application of the post-test occurred immediately after the intervention and the application of the follow-up after one month, whereas in the other studies the questionnaires were administered after two months of the intervention. Despite the differences in effect size values between the studies, it should be noted that all are well above of those observed by Layzer, Goodson, Bernstein and Price (2001) in their meta-analysis on parental support programs. In this meta-analysis the average effect of such programs on parental knowledge and attitudes was 0.23 , considered a small effect according to Cohen's (1988) classification.

Although the present results indicate only an increase in parents' knowledge about SBS, studies evaluating similar interventions suggest that this change may have a significant impact on parents' behavior towards baby's crying (Altman et al., 2011; R.G. Barr, Rajabali, Aragon, Colbourne, \& Brant, 2015; Dias et al., 2005). These authors observed that the parents started to move away from the baby in the face of the inconsolable cry more frequently after the intervention. In the study of R.G. Barr et al. (2015), it was observed that, after the implementation of a similar intervention to that of the present study in British Columbia (Canada), the number of visits to the Emergency Room due to complaints related to the baby's crying decreased. Finally, Altman et al. (2011) and Dias et al. (2005) observed a reduction in SBS cases in the western and northern regions of New York state (USA) after implementation of a SBS prevention program in maternity wards of the respective regions. In this sense, although the present study did not directly investigate the behavior of parents related to baby's crying or the incidence of SBS, the evidence observed in the cited studies suggests that the intervention may have had a positive impact on the protection of the participating babies.

In relation to the Factor Strategies to Deal with Crying Related to the Baby a pattern of increase in scores between the pre-test and the post-test similar for both groups was observed, although no significant differences were observed between the groups or between moments of evaluation. An explanatory hypothesis for such negative outcomes in the comparison of groups is related to the caregiver's experience with the care of the baby and the possible prior knowledge about strategies to calm the baby, related to the baby. Strategies like singing to the baby, showering or carrying 
him on the lap are commonly recommended by professionals and family members to the parents of newborns. Although they are already aware of such strategies, caregivers may not be sure about their effectiveness in calming the baby's crying. However, with daily care, caregivers can perceive the utility of these strategies, strengthening knowledge. In this sense, the increase of the knowledge observed in the present study may have been due to the experience of the caregivers with the baby.

The present study presents some limitations that must be considered when interpreting its results. In the first place, the lack of homogeneity of the sample in relation to the gender stands out: of the 252 participants, $77.5 \%$ were women. The literature indicates that men are the main aggressors in cases involving SBS (Coles \& Collins, 2009) which makes it essential to include them in SBS prevention programs. In addition, this sample had a high family income compared to the Brazilian population. According to the Demographic Census of $2010,3,23 \%$ of the population of the State of São Paulo receives more than 10 minimum wages, while $47.2 \%$ receive up to a minimum wage (Brazilian Institute of Geography and Statistics [Acronym in Portuguese: IBGE], 2010). In this study, only $15.1 \%$ of the participants presented income of up to a minimum wage and $5.9 \%$ of the participants presented income of more than 10 minimum wages. This lack of balance in relation to the family income of the sample prevents the generalization of the data to a wider population. One of the possible factors that may have influenced this imbalance is the difficulty of parents with lower schooling and income in responding to the questionnaire, causing 69 parents to withdraw from the study after the intervention, that is, they did not respond to the post-test. It should be noted that this difficulty was restricted to the application of the questionnaire, and participants were not withdrawn during the intervention. Considering that the intervention and the application of the questionnaires were done in groups, it was not possible to adapt the application of the instruments to the interview format.

Despite these limitations, the present study makes an important contribution to the development of evidence-based violence prevention programs in developing countries. Ward et al. (2016) propose four criteria for an intervention to be considered sustainable and with a public health approach: (1) aim to achieve the risk factors related to the outcome to be prevented; (2) there is evidence that intervention reduces such risk factors and undesired consequences; (3) must be economically efficient; and (4) there is evidence that it is possible to carry out the intervention on a large scale in the necessary context.

The present study seems to meet the criteria proposed by Ward et al. (2016), since infant crying and shaking behavior are the main risk factors for SBS (R.G. Barr, 2012) and the intervention proposed here contributed to an increase in parents' knowledge about these risk factors. Regarding the third criterion, the materials used in this intervention have a low cost for reproduction: the pamphlet cost $\mathrm{R} \$ 0,36$ and the DVD with the video cost $\mathrm{R} \$ 3,89$, totaling $\mathrm{R} \$ 4,25$. In addition, the intervention is simple, and can be performed by professionals who already carry out the follow-up of pregnant women during prenatal or postpartum infants. The intervention also fulfills the fourth criterion proposed by Ward et al. (2016), since it can be easily adopted as public policy with other health education actions carried out by the Unified Health System (acronym in Portuguese: SUS). Finally, it is concluded that a rapid and simple intervention, as proposed in this study, presents satisfactory results and potential to be used within the public health system.

\section{References}

Altman, R. L., Canter, J., Patrick, P. A., Daley, N., Butt, N. K., \& Brand, D. A. (2011). Parent education by maternity nurses and prevention of abusive head trauma. Pediatrics, 128(5), e1164-e1172. doi:10.1542/peds.2010-3260

Barr, R. G. (2012). Preventing abusive head trauma resulting from a failure of normal interaction between infants and their caregivers. Proceedings of the National Academy of Sciences of the United States of America, 109(Suppl. 2), 17294-17301. doi:10.1073/pnas.1121267109

Barr, R. G., Barr, M., Fujiwara, T., Conway, J., Catherine, N., \& Brant, R. (2009). Do educational materials change knowledge and behaviour about crying and shaken baby syndrome? A randomized controlled trial. CMAJ, 180(7), 727-733. doi:10.1503/cmaj.081419

Barr, R. G., Rajabali, F., Aragon, M., Colbourne, M., \& Brant, R. (2015). Education about crying in normal infants is associated with a reduction in pediatric emergency room visits for crying complaints. Journal of Developmental and Behavioral Pediatrics, 36(4), 252-257. doi:10.1097/DBP.0000000000000156

Barr, R. G., Rivara, F. P., Barr, M., Cummings, P., Taylor, J., Lengua, L. J., \& Meredith-Benitz, E. (2009). Effectiveness of educational materials designed to change knowledge and behaviors regarding crying and shaken-baby syndrome in mothers of newborns: A randomized, controlled trial. Pediatrics, 123(3), 972-980. doi:10.1542/peds.2008-0908

Cohen, J. W. (1988). Statistical power analysis for the behavioral sciences. Hillsdale, NJ: Lawrence Erlbaum.

Coles, L., \& Collins, L. (2009). Including fathers in preventing non-accidental head injury. Community Practitioner: The Journal of the Community Practitioners' \& Health Visitors'Association, 82(4), 20-23.

Deyo, G., Skybo, T., \& Carroll, A. (2008). Secondary analysis of the "Love Me... Never Shake Me" SBS education program. Child Abuse \& Neglect, 32(11), 1017-1025. doi:10.1016/j.chiabu.2008.02.006

Dias, M. S., Smith, K., DeGuehery, K., Mazur, P., Li, V., \& Shaffer, M. L. (2005). Preventing abusive head trauma among infants and young children: A Hospital-based, parent education program. Pediatrics, 115(4), e470-e477. doi:10.1542/peds.2004-1896 
Fernandes, V. M. A., Silva, N. L., \& Javorski, M. (2010). Prevenção da Síndrome do Bebê Sacudido: Conhecimento da equipe de saúde da família [Prevention of Shaken Baby Syndrome: Staff knowledge of family health]. Nursing (São Paulo), 13(145), 304-308.

Foley, S., Kovács, Z., Rose, J., Lamb, R., Tolliday, F., SimonsCoghill, M., ... Sarten, T. (2013). International collaboration on prevention of shaken baby syndrome - an ongoing project/ intervention. Paediatrics and International Child Health, 33(4), 233-238. doi:10.1179/2046905513Y.0000000093

Fujiwara, T. (2015). Effectiveness of public health practices against shaken baby syndrome/abusive head trauma in Japan. Public Health, 129(5), 475-482. doi:10.1016/j.puhe.2015.01.018

Fujiwara, T., Yamada, F., Okuyama, M., Kamimaki, I., Shikoro, N., \& Barr, R. G. (2012). Effectiveness of educational materials designed to change knowledge and behavior about crying and shaken baby syndrome: A replication of a randomized controlled trial in Japan. Child Abuse \& Neglect, 36(9), 613-620. doi:10.1016/j.chiabu.2012.07.003

Hardcastle, K. A., Bellis, M. A., Hughes, K., \& Sethi, D. (2015). Implementing child maltreatment prevention programmes: What the experts say. Copenhagen, Denmark: World Health Organization. Retrieved from http://www.euro.who.int/_data/assets/pdf_ file/0009/289602/Maltreatment_web.pdf?ua $=1$

Instituto Brasileiro de Geografia e Estatística. (2010). Censo demográfico 2010: Resultados gerais da amostra [Demographic censos 2010: Overall sample results]. Rio de Janeiro, RJ: IBGE.

Layzer, J. I., Goodson, B. D., Bernstein L., \& Price, C. (2001). National evaluation of family support programs. Final report volume A: The meta-analysis. Cambridge, MA: Abt Associates.

Lee, C., Barr, R. G., Catherine, N., \& Wicks, A. (2007). Age-related incidence of publicly reported shaken baby syndrome cases: Is crying a trigger for shaking? Journal of Developmental and Behavioral Pediatrics, 28(4), 288-293. doi:10.1097/DBP.0b013e3180327b55

Lopes, N. R. L. (2017). Trauma craniano violento pediátrico: Estratégias de avaliação e prevenção [Pediatric abusive head trauma: evaluation and prevention strategies]. (Doctoral thesis, Universidade Federal de São Carlos, São Carlos/SP, Brasil). Retrieved from https://repositorio.ufscar.br/handle/ufscar/9079.

Lopes, N. R. L., Eisenstein, E., \& Williams, L. C. A. (2013). Abusive head trauma in children: A literature review. Jornal de Pediatria, 89(5), 426-433. doi:10.1016/j.jped.2013.01.011

Lopes, N. R. L., \& Williams, L. C. A. (2016a). Avaliação do conhecimento sobre trauma craniano violento por pais brasileiros [Brazilian parent's knowledge on abusive head trauma]. Psicologia: Teoria e Pesquisa, 32(2), 1-11. doi:10.1590/0102-3772e32223
Lind, K., Toure, H., Brugel, D., Meyer, P., Laurent-Vannier, A., \& Chevignard, M. (2016). Extended follow-up of neurological, cognitive, behavioral and academic outcomes after severe abusive head trauma. Child Abuse \& Neglect, 51, 358-367.doi:10.1016/j.chiabu.2015.08.001

Monsalve-Quintero, D. S., \& Alvarado-Romero, H. J. (2010). Efecto de una intervención educativa dirigida a cuidadores de niños menores de dos años sobre la prevención del síndrome del niño sacudido [Effect of patient education and support for caregivers of children under two years on the prevention of shaken baby syndrome]. Investigación en Enfermaria: Imagen y Desarrollo, 12(1), 43-58. Retrieved from http://revistas.javeriana.edu.co/index.php/ imagenydesarrollo/article/viewFile/1624/1046

Morrill, A. C., McElaney, L., Peixotto, B., VanVleet, M., \& Sege, R. (2015). Evaluation of All Babies Cry, a second generation universal abusive head trauma prevention program. Journal of Community Psychology, 43(3), 296-314. doi:10.1002/jcop.21679

Parks, S. E., Annest, J. L., Hill, A. H., \& Karch, D. L. (2012). Pediatric abusive head trauma: Recommended definitions for public health surveillance and research. Atlanta, GA: Centers for Disease Control and Prevention.

Rodríguez, B. M., Marrero, A. P., Ortiz, E. D., Rios, J., \& Rivera, G. M. (2011). Proyecto manos: Mas abrazos, no sacudidas [The hand project: More hugs, no shakings]. Boletin de la Asociacion Medica de Puerto Rico, 103(1), 9-13.

Runyan, D. K., Shankar, V., Hassan, F., Hunter, W. M., Jain, D., Paula, C. S., ... Bordin, I. A. (2010). International variations in harsh child discipline. Pediatrics, 126(3), e701-e711. doi:10.1542/peds.2008-2374

Russell, B. S., Alpert, L., \& Trudeau, J. J. (2009).Child abuse prevention during infancy: Intervention implications for caregivers' attitudes toward emotion regulation. Journal of Human Behavior in the Social Environment, 19(5), 540-553. doi:10.1080/10911350902992789

Simonnet, H., Laurent-Vannier, A., Yuan, W., Hully, M., Valimahomed, S., Bourennane, M., \& Chevignard, M. (2014). Parents' behavior in response to infant crying: Abusive head trauma education. Child Abuse and Neglect, 38(12), 1914-1922. doi:10.1016/j.chiabu.2014.06.002

Tasar, M. A., Bilge, Y. D., Sahin, F., Camurdan, A., Beyazova, U., Polat, S., \& Ilhan, M. N. (2015). Shaken Baby Syndrome prevention programme: A pilot study in Turkey. Child Abuse Review, 24(2), 120-128. doi:10.1002/car.2326

Tolliday, F., Martine, S., Foley, S., Benson, S., Stephens, A., \& Rose, D. (2010). From inspiration to action: The Shaken Baby prevention project in Western Sydney. Communities, Children and Families Australia, 5(2), 31-47. Retrieved from https://www.researchgate.net/publication/275338139_ From_Inspiration_to_Action_The_Shaken_Baby_ Prevention_Project_in_Western_Sydney 
Ward, C., Sanders, M. R., Gardner, F., Mikton, C., \& Dawes, A. (2016). Preventing child maltreatment in low- and middle-income countries: Parent support programs have the potential to buffer the effects of poverty. Child Abuse \& Neglect, 54, 97-107. doi:10.1016/j.chiabu.2015.11.002

Nahara Rodrigues Laterza Lopes has a Doctorate Degree in Psychology from the Universidade Federal de São Carlos.

Suélen Mariana Górni has a undergraduate degree in Psychology from the Universidade Federal de São Carlos.

Victor Oliver Mattar has a undergraduate degree in Psychology from the Universidade Federal de São Carlos.

Lucia Cavalcanti de Albuquerque Williams is a Professor of the Universidade Federal de São Carlos.

Received: Jan. 24, 2017

1st Revision: Sep. 05, 2017

Approved: Oct. 25, 2017

How to cite this article:

Lopes, N. R. L., Górni, S. M., Mattar, V. O., \& Williams, L. C. A. (2018). Assessment of a bef itervention with parents to prevent shaken baby syndrome. Paidéia (Ribeirão Preto), 28, e2823. doi:http://dx.doi.org/10.1590/1982-4327e2823 